condition that can be cured and that gay people can be changed.

In the past it was thought to be abnormal to be left handed and children were forced to become right handed in spite of the trauma. The fact that homosexuality is just as natural seems to be difficult for many to accept.

I am saddened by the stories I hear from parents who, immediately they find they have a gay son or daughter, seek help from their general practitioner. Some years ago a man of 19 went to his family doctor for advice about his homosexuality. The general practitioner told him to stop being so silly and to go away and find himself a nice girl. He did, married, fathered two children-and remained homosexual. The only change was the creation of far more problems for a larger number of people when, with a little understanding, he could have "found himself" at a much earlier age. Fortunately, he now has a partner of the same sex and is happy. This happened many years ago and one would have thought things might have changed if only a little.

Another general practitioner told a mother recently that she could talk to him at any time to discuss how she felt about the son she had just found to be gay-she felt suicidal. He closed the conversation by saying, "Thank God I've only three girls." I only hope he never has to go through the trauma of finding one of those girls to be lesbian. Other general practitioners have refused to have homosexuals on their lists. All these events happened to people I know personally, who were upset and degraded by the treatment they received from the medical people they consulted.

The problem seems to be lack of knowledge on a subject that society as a whole should be made more aware of. No amount of psychiatry psychology, or psychotherapy can change a homosexual into a heterosexual. Ask heterosexuals if they could turn gay and they will reply that this is impossible. So why is it thought to be possible for a homosexual to turn heterosexual? Until the day when children are taught that there is no such thing as a "normal" person and that we are all individuals then homosexuals will continue to be looked on as "different" if not worse-as perverts and deviants

Only therapy and counselling carried out by either a gay person or one sympathetic to gay people can attempt to help if there is a problemand often there is no problem whatsoever; it is what other people make of the situation. There is much help available, but are general practitioner prepared to look for those who really can help when help is needed? Maybe if they found time to talk to parents who run the groups set up for those with homosexual offspring they could learn a lot.

Certainly there is a need for attitudes to be changed, and not by the homosexuals. No one would choose the life of a homosexual, which is often fraught with prejudice and injustice. For this reason I have withheld my name, to protect the identity of my family.

Parents' Friend

c/o CVS

9-25 Sunbridge Road

Bradford BD1 2AY

I doubt on the basis of personal experience, the testimony of others, as well as the reported admis sion of your own editorial staff whether there is much likelihood of having a contribution critical of homosexuality published in the journal. The editorial by Dr John Bancroft ( 30 July, p 308) is, however, such an extraordinary example of special pleading that its prominence in a scientific journal demands comment.

Dr Bancroft in the space of one page flits in dilettante fashion through a mishmash of medical history, sociology, religion, politics, zoology, and anthropology to reach the conclusion he originally intended that "a homosexual lifestyle is compatible with all the criteria of health." Let us concentrate on the central question posed by Dr Bancroft-is living a homosexual lifestyle bad for your health? - and answer as honest doctors. The dangers of this lifestyle are matters of fact not of opinion. They were clearly identified before AIDS appeared and interestingly enough became a major health problem in the precise communities where AIDS was shortly to make its appearance in its most devastating form. Thus San Francisco was the venue before 1977 of an increased prevalence of shigellosis, amoebiasis, and viral hepatitis among young men practising frequent orogenital and oroanal sexual contact. ${ }^{1}$

Why cannot we as doctors face the issue truthfully on a biological level? Our professed amorality should not blind us to plain evidence. I is "natural" to place food in our mouths, to breathe through our nostrils, and to defecate through the rectum. The penis and vagina are peculiarly useless organs apart from the one function for which they are eminently appropriate.

Department of Pathology,

D E B POWELL

Bridgend,

Mid Glamorgan CF31 IRQ

1 Dritz SK, Ainsworth TE, Garrard WF, et al. Patterns of sexually Tonsmited enteric disease in a city Lancet 1977;ii:3-4. Powell DEB. The gay life. Lancet 1977;ii: 140 .

* In his mention of "the reported admission of your own editorial staff" Dr Powell is presumably referring to "Is there a homosexual conspiracy?" by Graham Turner (Sunday Telegraph, 5 June 1988, p 17-8). In fact, in our interview with Mr Turner Richard Smith and I failed to get our editorial policy across-which is based on exactly the same principles as we apply to any other contentious subject: both "sides" must be allowed to make their point once, but thereafter any further publication will depend on new matter, particularly the inclusion of data. Given a rejection rate of $60 \%$ for letters submitted to the correspondence column, there is little point in repeating the same opinion and excluding other contributions. STEPHEN LOCK, editor BMF.

\section{Cervical intraepithelial neoplasia}

In his editorial $\mathrm{Mr} \mathrm{J} \mathrm{A} \mathrm{Jordan} \mathrm{crystallises} \mathrm{the}$ argument for a multicentre comparative study of cytology and colposcopy in the management of minor grade cervical neoplasia (2 July, p 6). The high prevalence of minor cervical lesions that may not always be identified by cytology ${ }^{1}$ and the observation that low grade cytological abnormality may be associated frequently with areas of high grade cervical intraepithelial neoplasia ${ }^{2}$ contrasts sharply with evidence that properly organised cytological screening can offer effective protection.

Our experience in Islington is that both of these apparently contradictory findings are correct and that there may be only questionable benefit from the colposcopic assessment of minor grade cervical abnormality. Long term studies of the natural course of cervical disease are essential, but it is also necessary to obtain rapidly accurate information before public pressure overtakes informed judgment. Theoretical computations based on the mortality from invasive disease imply an extremely low risk of progression to malignancy for much of this disease but could be wildly inaccurate as they take no account of the effect of screening and treatment in keeping the disease at bay or the possibility of a rapidly increasing epidemic of this disease. ${ }^{+}$A satisfactory end point for studies of progression is difficult. The development of invasive disease is clearly unacceptable ethically, and the histological diagnosis of cervical intraepithelial neoplasia grade III is prone to error because of the considerable variation in size and histological pattern of these lesions.

We have addressed this problem with a multicentre comparative study of patients who presented two or more years ago with mild dyskaryosis. Carefully matched groups of patients who were managed by cytological surveillance alone or by colposcopy and treatment are being compared. With colposcopic assessment in conjunction with cervicography, dot blot hybridisation for human papillomavirus, and colposcopic or cone biopsy it is possible to study not only mortality but also morbidity in terms of extent as well as grade of disease. The cost effectiveness of each approach as well as patient anxiety and satisfaction are being assessed.

The project is supported by the Jules Thorn Trust at the Middlesex Hospital with help from the Imperial Cancer Research Fund, the North East Thames Regional Health Authority, and colleagues from Islington, Milton Keynes, Stoke Mandeville, and west London. We believe that this study could well provide the basis for a continuing prospective multicentre national study of a range of alternative management policies.

DAVID JENKINS M H JONES

Department of Cytopathology,

Whittington Hospital,

London N19

1 Giles JA, Hudson R, Crow J, Williams D, Walker P. Colposcopic assessment of the accuracy of cervical cytology screening. BrMed f 1988;296:1099-102.

2 Tay SK, Jenkins D, Singer A. Management of squamous atypia (borderline nuclear abnormalities): repeat cytology or colposcopy? Aust NZ J Obstet Gynaecol 1987;27:140-1.

3 Anderson GH, Boyes DA, Benedet JL, et al. Organisation and results of the cervical cytology screening programme in British Columbia, 1955-85. Br Med f 1988;296:975-8.

4 Smith A. Cervical cytology screening. Br Med f 1988;296:1670.

\section{Colposcopy in teenagers}

It seems that several pertinent points about screening were not taken into consideration by $\mathrm{Mr} \mathrm{N} \mathrm{G}$ Haddad and others (2 July, p 29), who concluded that cervical cytology screening should be extended to include teenagers. Their argument is based on a colposcopy clinic database, in which $3.3 \%$ of the observation group were less than 20 years of age. One third of these patients were or had been pregnant, $61 \%$ were smokers, and $24 \%$ had been referred from genitourinary medicine clinics. It is therefore apparent that their conclusions are based on a highly selected and atypical subpopulation of sexually active teenage girls. Despite this selection by known risk factors the incidence of abnormal cervical cytology in this group was noted to be less than for their overall population $(46 / 1000 v 65 / 1000)$. This is similar to our own observations of a previously unscreened teenage population attending the Birmingham Brook Advisory Centre. The incidence of cervical cytological abnormality in this group was $51 / 1000$.

The objective of screening is to prevent death from cervical cancer. Although there have been reports of an increasing incidence of cervical cancer in young women, few deaths occur before the age of 25 , and it might be anticipated that introducing screening for those in their early to mid-20s would still detect, at a preventable stage, those teenagers who harboured cervical epithelial abnormalities in their teens. The cases prevented by introducing screening in the teens would be few, yet the increased clinical effort and hence cost per unit would be large.

To put the argument in its proper context the incidence of cervical cytological abnormality in the whole of the sexually active teenage population 